This report is a preprint of an article submitted to a journal for publication. Because of changes that may be made before formal publication, this preprint is made available with the understanding that it will not be cited or reproduced without the permission of the author.

\title{
Shapes of Nonbuoyant Round Luminous Hydrocarbon/Air Laminar Jet Diffusion Flames
}

\author{
K.-C. LIN, G. M. FAETH* \\ The University of Michigan. Amn Arbor, Michigan 48109
}

P. B. SUNDERLAND, D. L. URBAN, and Z.-G. YUAN

NASA Lewis Research Center, Cleveland, Ohio 44135

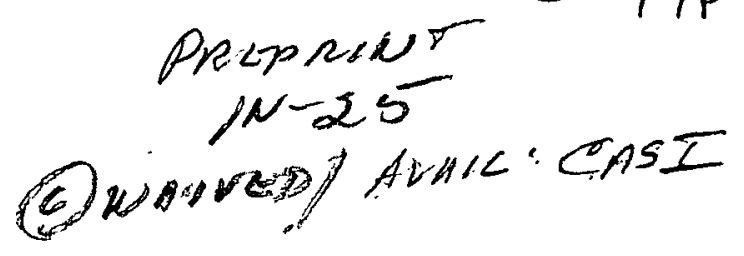

\begin{abstract}
The shapes (luminous flame boundaries) of round luminous nonbuoyant soot-containing hydrocarbon/air laminar jet diffusion flames at microgravity were found from color video images obtained on orbit in the Space Shuttle Columbia. Test conditions included ethylene- and propane-fueled flames burning in still air at an ambient temperature of $300 \mathrm{~K}$, ambient pressures of $35-130 \mathrm{kPa}$, initial jet diameters of 1.6 and $2.7 \mathrm{~mm}$, and jet exit Reynolds numbers of 45-170. Present test times were 100-200 s and yielded steady axisymmetric flames that were close to the laminar smoke point (including flames both emitting and not emitting soot) with luminous flame lengths of $15-63 \mathrm{~mm}$. The present soot-containing flames had larger luminous flame lengths than earlier ground-based observations having similar burner configurations: $40 \%$ larger than the luminous flame lengths of soot-containing low gravity flames observed using an aircraft (KC-135) facility due to reduced effects of accelerative disturbances and unsteadiness; roughly twice as large as the luminous flame lengths of sootcontaining normal gravity flames due to the absence of effects of buoyant mixing and roughly twice as large as the luminous flame lengths of soot-free low gravity flames observed using drop tower facilities due to the presence of soot luminosity and possible reduced effects of unsteadiness. Simplified expressions to estimate the luminous flame boundaries of round nonbuoyant laminar jet diffusion flames were obtained from the classical analysis of Spalding (1979); this approach provided successful correlations of flame shapes for both soot-free and soot-containing flames, except when the soot-containing flames were in the opened-tip configuration that is reached at fuel flow rates near and greater than the laminar smoke point fuel flow rate. (1) 1998 by The Combustion Institute
\end{abstract}

\section{NOMENCLATURE}

$C_{\mathrm{f}} \quad$ empirical flame length parameter

$d \quad$ jet exit diameter

D mass diffusivity

$L_{\mathrm{o}} \quad$ distance from jet exit to virtual origin

$L_{f} \quad$ distance from jet exit to Juminous flame tip

in burner mass flow rate

$p \quad$ pressure

Re jet Reynolds number, $4 \dot{m} /(\pi d \mu)$

$r \quad$ radial distance

Sc Schmidt number, $v / D$

$t_{\mathrm{ch}} \quad$ characteristic residence time, $2 L_{\mathrm{f}} / u_{\mathrm{o}}$

$u_{0}$ mean burner exit velocity, 4 $\dot{m} /\left(\pi \rho_{v} d^{2}\right)$

$w \quad$ luminous flame diameter

$w_{\mathrm{MAX}}$ maximum luminous flame diameter

$w_{1 / 2} \quad$ luminous flame diameter at $\zeta=1 / 2$.

$Z_{\mathrm{st}} \quad$ stoichiometric mixture fraction

$z \quad$ streamwise distance

*Corsesponding author. E-mail: gmfaeth@umich.edu

COMBUSTION AND FLAME 116:415-431 (1999)

(1) 1998 by The Combustion Institute

Puhlished by Elsevier Science Inc. $\zeta \quad$ normalized streamwise distance, Eq. 6

$\mu \quad$ dynamic viscosity

$\nu \quad$ kinematic viscosity

$\rho$ density

\section{Subscripts}

o burner exit condition

\section{INTRODUCTION}

Observations of nonbuoyant laminar diffusion flames are described which were obtained at microgravity on board the orbiting Space Shuttle Columbia. Laminar diffusion flames are of interest because they provide model flame systems that are far more tractable for theoretical and experimental studies than more practical turbulent diffusion flames. Laminar diffusion flames also merit study because understanding their transport and chemical reaction processes is a necessary precursor to understanding these processes in turbulent diffusion flames. In addi- 
tion, many aspects of laminar diffusion flames have direct relevance to turbulent diffusion flames by application of the laminar flamelet concept of turbulent diffusion flames [1]. The present study specifically considered the shapes (the luminous flame boundaries) of laminar diffusion flames, which is a flame property that has attracted numerous investigations since the classical study of Burke and Schumann [2]. This interest follows because simple nonintrusive measurements yield flame shapes, which can be used to evaluate theories of laminar flame processes and predictions of laminar flame structure. A concern about measurements of the shapes of laminar diffusion flames at normal gravity, however, involves the intrusion of disturbances due to buoyancy because they are not relevant to practical diffusion flames, which generally are not buoyant due to their large velocities. These buoyant disturbances also tend to obscure important properties of the nonbuoyant flames that are of the greatest interest [3]. Thus, the present investigation sought measurements of the shapes of classical steady nonbuoyant round laminar jet diffusion flames by exploiting the long-term microgravity environment of an orbiting space shuttle. The objectives of this paper are to document these measurements and to develop a summary of the results, convenient for use by others, based on simplified analysis of nonbuoyant laminar jet diffusion flames.

Past measurements of the shapes of nonbuoyant laminar jet diffusion flames have been carried out using either drop towers to provide microgravity environments [4-13] or aircraft facilities [14] to provide low-gravity environments. The earliest work along these lines was a series of studies of hydrocarbon-fueled laminar jet diffusion flames using a $2.2 \mathrm{~s}$ free-fall (drop) tower due to Cochran and co-workers [4-6]. They ignited the flames before putting the experiment package into free-fall and observed an immediate reduction of the luminous flame length when the flame was exposed to the low gravity environment. The subsequent transient development of the flame shape, combined with the relatively short duration of the microgravity environment, raised concerns about the results due to potential effects of unsteady flame development. Another problem with measure- ments of the shapes of hydrocarbon-fueled flames is that the luminosity of these flames is mainly caused by glowing soot particles, particularly along the flame axis where luminous flame lengths are normally measured. Thus, the relationship between luminous flame dimensions and the location of the flame sheet (where the local mixture fraction is stoichiometric) is an issue because the latter generally is associated with predictions of laminar flame shapes. Past measurements of the flame structure and soot properties of weakly buoyant and buoyant round laminar jet diffusion flames burning in still or slowly moving air provide some information about luminous and stoichiometric flame lengths [15-18]. These observations indicate that ratios of luminous- to stoichiometric-flame lengths are in the range $0.9-1.8$, with these ratios increasing as the laminar smoke point flame length is approached [15-18]. This behavior comes about because soot oxidation begins at slightly fuel-rich conditions and can continue in the fuel-lean region for a time before either the soot is consumed (non-soot-emitting flames), or the soot oxidation reactions are quenched (soot-emitting flames), with luminous flame lengths varying accordingly [15].

Studies following the work of Cochran and coworkers [4-6] due to Bahadori and coworkers [7-12] sought to resolve potential effects of transient flame development and soot luminosity on measurements of the shape of nonbuoyant round laminar jet diffusion flames using both $2.2 \mathrm{~s}$ and $5.2 \mathrm{~s}$ drop towers. In order to minimize problems of transient behavior, they ignited the flames shortly after the experimental package was released and observed nearly steady flame shapes near the end of free fall. Nevertheless, temperature fields and radiation emissions of the flames were still changing at the end of the $5.2 \mathrm{~s}$ free-fall periods for the flame conditions that they considered, implying that transient effects had still not fully relaxed during the available microgravity test time.

Sunderland et al. [14] considered the luminous flame lengths of nonbuoyant soot-containing round laminar jet diffusion flames as part of a study of the laminar smoke point properties of nonbuoyant laminar diffusion flames. These experiments were carried out in a KC-135 aircraft facility that provided roughly $20 \mathrm{~s}$ at low gravity 
by flying parabolic trajectories. It was hoped that these long low-gravity test times would minimize effects of transient flame development on observed flame shapes. These flames all approached laminar smoke point conditions and should be representative of long luminous flame lengths discussed earlier. Unfortunately, the $\mathrm{KC}-135$ aircraft facility provided a rather disturbed low-gravity environment (with significant $g$-jitter) with the accompanying unsteady effects influencing both flame shapes and laminar smoke point properties [14].

In spite of potential effects of unsteadiness for the ground-based studies of nonbuoyant laminarjet diffusion flames, however, Cochran and co-workers [4-6], Bahadori and co-workers [7-12], and Sunderland et al. [14] all observed a linear correlation between luminous flame lengths and fuel flow rates, independent of jet exit diameter, for each fuel burning in air. This behavior also is typical of the luminous flame lengths of buoyant round laminar jet diffusion flames [19]. Thus, to the extent that this linear relationship is retained for truly steady and nonbuoyant laminar jet diffusion flames, it offers an important characteristic useful for testing flame shape predictions.

Most recently, Sunderland et al. [13] sought to avoid problems of both unsteadiness and soot luminosity by measuring the shape of soot-free laminar jet diffusion flames using a $2.2 \mathrm{~s}$ drop tower facility. Ambient pressures, jet exit diameters and fuel flow rates were controlled to provide soot-free (blue) laminar jet diffusion flames having relatively small characteristic flame residence times so that unsteady effects were potentially minimized. These results for soot-free flames exhibit generally shorter flame lengths than corresponding soot-containing flames but the limited flame development period at microgravity still introduces uncertainties in the flame shape measurements due to potential effects of transient flame development.

The shapes of laminar jet diffusion flames also have attracted significant theoretical attention. Measured flame lengths for both soot-free and soot-containing flames have been used to develop empirical models and to evaluate theoretical predictions for a range of buoyant conditions. The most well-known empirical model for laminar diffusion flames is the linear correlation between the luminous flame length and the corresponding fuel flow rate [19] that was mentioned earlier. Several laminar diffusion flame models of varying complexity also have been proposed [20-26] that successfully predict the linear correlation between stoichiometric flame lengths and the fuel flow rates (or equivalently between the stoichiometric flame length normalized by the jet exit diameter and the jet exit Reynolds number). Among these, the analysis of Spalding [22] (which is described in some detail by Kuo [23]) offers a potentially simple and robust method for estimating the shapes of steady nonbuoyant round laminar jet diffusion flames. Nevertheless, modifications of this approach to deal with soot-containing flames (as opposed to soot-free flames), the capabilities of this approach to estimate (or correlate) all flame shape properties (as opposed to simply luminous flame lengths), and the performance of this approach for truly steady and nonbuoyant round laminar jet diffusion flames, are all issues that need to be addressed.

Based on the previous discussion of the literature, several aspects of the shape of nonbuoyant round laminar jet diffusion flames need to be resolved, as follows: to what extent have past observations using ground-based microgravity facilities been affected by transient development or disturbances of the flames, to what extent have differences between stoichiometric conditions and the limits of visible luminosity from soot affected estimates of flame shapes, and to what extent can flame shape data be predicted (correlated) by simplified analysis? These issues were addressed during the present investigation based on observations of nonbuoyant round laminar jet diffusion flames at longduration microgravity conditions on board the orbiting Space Shuttle Columbia, and by evaluation of simplified analysis of flame structure using these observations, with the following specific objectives:

1. Measure the shapes (luminous flame boundaries), and associated properties such as luminous flame lengths and diameters, for various fuel types, jet exit diameters, jet exit flow rates (Reynolds numbers), and ambient pressures. 
2. Compare the present measurements with earlier ground-based observations having similar burner conditions in order to help quantify effects of transient flame development, flow disturbances ( $\mathrm{g}$-jitter), soot luminosity, and buoyancy on flame shape properties.

3. Exploit the measurements in order to evaluate the simple flame shape analysis of Spalding [22] and develop this approach to provide convenient correlations of flame shape measurements for use by others.

Present observations were limited to soot-containing ethylene- and propane-fueled flames burning in still dry air, at conditions near the laminar smoke point.

The following description of the study begins with consideration of experimental methods, test conditions, and theoretical methods. Results are then discussed, considering luminous flame lengths, luminous flame diameters, and luminous flame shapes, in turn. Major conclusions are summarized at the end of the article.

\section{EXPERIMENTAL METHODS}

Experimental methods will be only briefly described; see Urban et al. [27] for more details. The laminar jet diffusion flames were stabilized at the exit of round fuel nozzles located along the axis of a windowed cylindrical chamber. The chamber had a diameter of $400 \mathrm{~mm}$, a maximum length of $740 \mathrm{~mm}$, an internal volume of 0.082 $\mathrm{m}^{3}$, and was operated at pressures of 35-130 $\mathrm{kPa}$. The chamber was filled with oxygen/nitrogen mixtures to provide the nominal composition of dry air ( $21 \pm 1 \%$ oxygen by volume). The pressure, temperature, and composition of the gas surrounding the test flames all varied slightly over the flame burning periods due to the limited amount of air within the closed chamber. The greatest change involved the composition of gas within the chamber but even this was controlled so that the maximum oxygen consumption never exceeded $2 \%$ by volume during any flame test. These conditions were maintained by venting the chamber to space and adding fresh dry air (as needed) prior to each test.

Two fuel nozzles, consisting of constant diam- eter cylindrical stainless steel tubes having inside diameters of 1.6 and $2.7 \mathrm{~mm}$, wall thicknesses of $0.28 \mathrm{~mm}$, and lengths of $148 \mathrm{~mm}$ from the inlet plenum, were used. The inlets of these nozzles had flow straighteners while the overall length-to-diameter ratios of the passages were greater than 55:1, which was sufficient to yield fully developed laminar pipe flow at the nozzle exit for the present test conditions $\left(172 \geq R e_{\mathrm{o}}\right.$ $\geq 46$ ). The test fuels were stored in cylinders and were delivered to the nozzles through solenoid valves and a mass flow rate controller and sensor. The flames were ignited by a hot wire coil that was retracted from the nozzle exit once ignition was successful.

Several measurements were made to monitor flame operation as follows: fuel flow rate with an accuracy of $0.8 \%$, fuel temperature at the nozzle inlet with an accuracy of $\pm 1.5 \mathrm{~K}$, chamber pressure with an accuracy of $1.2 \%$, and chamber gas temperature (far from flames) with an accuracy of $\pm 1 \mathrm{~K}$. These measurements were recorded at a rate of approximately $1 \mathrm{~Hz}$.

Flame shapes (luminous flame boundaries) were measured from images obtained using a standard color CCD video camera (Hitachi, Model KP-C553). The camera had a $125 \times 164$ $\mathrm{mm}$ field of view and a depth of field of $25 \mathrm{~mm}$ centered on the flame axis. The spatial resolution of the recorded images was better than 0.3 $\mathrm{mm}$. It was not possible to adjust image brightness on orbit; therefore, it was necessary to select camera settings so that the flames having the smallest levels of luminosity (found from ground-based tests at microgravity using a freefall facility) could still be observed. This implied that the flame images were generally overexposed although they still provided sharp images of luminous flame boundaries. Flame images were recorded at a rate of 30 images/s. The flames were unusually symmetric; nevertheless, the shapes reported here represent average positions for the two sides.

\section{TEST CONDITIONS}

The test conditions of the present flames are summarized in Table 1. A total of 21 flames were observed, yielding the following ranges of test properties: ethylene- and propane-fueled 
TABLE 1

Summary of Test Conditions

\begin{tabular}{|c|c|c|c|c|c|c|c|}
\hline Test ${ }^{a}$ & $\underset{(\mathrm{kPa})}{p}$ & $\underset{(\mathrm{mg} / \mathrm{s})}{\dot{m}}$ & $\begin{array}{c}u_{0}{ }^{h} \\
(\mathrm{~mm} / \mathrm{s})\end{array}$ & $\begin{array}{l}R e_{0} \\
(-)\end{array}$ & $\begin{array}{l}t_{\mathrm{ch}} \\
(\mathrm{ms})\end{array}$ & $\begin{array}{c}L_{\mathrm{f}} \\
(\mathrm{mm})\end{array}$ & $\begin{array}{l}w_{\operatorname{MAX}} \\
(\mathrm{mm})\end{array}$ \\
\hline \multicolumn{8}{|c|}{$\mathrm{C}_{2} \mathrm{H}_{4} /$ air flames, $d=1.6 \mathrm{~mm}, Z_{\mathrm{st}}=0.0636:$} \\
\hline $01 E^{*}$ & 100 & 1.84 & 820 & 138 & 121 & 49.3 & 13.7 \\
\hline 03E* & 50 & 1.84 & 1630 & 138 & 77 & 63.0 & 14.2 \\
\hline $01 \mathrm{E}$ & 100 & 0.71 & 320 & 54 & 130 & 20.6 & 12.6 \\
\hline $02 \mathrm{E}$ & 50 & 0.76 & 670 & 57 & 53 & 17.7 & 13.1 \\
\hline $03 \mathrm{E}$ & 50 & 1.29 & 1140 & 97 & 64 & 36.5 & 13.8 \\
\hline $04 \mathrm{E}$ & 65 & 0.91 & 620 & 68 & 86 & 26.5 & 13.1 \\
\hline $14 \mathrm{E}$ & 80 & 0.67 & 370 & 50 & 97 & 18.0 & 12.9 \\
\hline $15 E$ & 100 & 0.61 & 270 & 46 & 109 & 14.7 & 11.5 \\
\hline $16 \mathrm{E}$ & 65 & 0.74 & 510 & 56 & 75 & 19.0 & 13.4 \\
\hline 17E & 35 & 1.34 & 1690 & 100 & 40 & 34.0 & 14.7 \\
\hline \multicolumn{8}{|c|}{$\mathrm{C}_{2} \mathrm{H}_{4} /$ air fames, $d=2.7 \mathrm{~mm}, Z_{\mathrm{st}}=0.0636$ : } \\
\hline O5E & 65 & 1.14 & 270 & 51 & 215 & 29.1 & 21.4 \\
\hline $06 \mathrm{E}$ & 80 & 1.16 & 230 & 51 & 269 & 30.3 & 20.9 \\
\hline $07 \mathrm{E}$ & 100 & 1.08 & 170 & 48 & 302 & 25.5 & 19.6 \\
\hline O8E & 50 & 1.38 & 430 & 62 & 173 & 37.3 & 21.4 \\
\hline \multicolumn{8}{|c|}{$\mathrm{C}_{3} \mathrm{H}_{8} /$ air flames, $d=1.6 \mathrm{~mm}, Z_{\mathrm{st}}=0.0602 \mathrm{z}$} \\
\hline $09 P$ & 130 & 0.78 & 170 & 73 & 277 & 23.3 & 17.4 \\
\hline $10 \mathrm{P}$ & 50 & 1.82 & 1020 & 172 & 120 & 61.4 & 18.8 \\
\hline $11 \mathrm{P}$ & 65 & 1.22 & 530 & 116 & 144 & 38.1 & 17.4 \\
\hline $12 P$ & 100 & 0.88 & 250 & 83 & 218 & 27.1 & 16.6 \\
\hline $13 \mathrm{P}$ & 80 & 1.04 & 370 & 99 & 177 & 32.4 & 17.2 \\
\hline $18 \mathrm{P}$ & 80 & 0.82 & 290 & 78 & 164 & 23.9 & 16.9 \\
\hline $19 \mathrm{P}$ & 100 & 0.71 & 200 & 67 & 191 & 19.0 & 16.1 \\
\hline
\end{tabular}

${ }^{a} 01 E^{*}$ and $03 E^{*}$ were carried out on flight STS-83, all other tests were carried out on flight STS-94. Only tests $01 E^{*}, 03 E^{*}$, and $01 \mathrm{E}$ involved soot-emitting flames in the period when flame shape observations were made.

${ }^{b}$ Mean velocity based on fuel density at jet exit (nominal pressure and $300 \mathrm{~K}$ ).

' Mean Reynolds number based on fuel viscosities at jet exit $(300 \mathrm{~K})$, i.e., $10.6 \mathrm{mg} /(\mathrm{sm})$ for ethylene and $8.4 \mathrm{mg} /(\mathrm{sm})$ for propane.

flames in burning dry air, ambient temperatures and pressures of $300 \mathrm{~K}$ and $35-130 \mathrm{kPa}$, jet exit diameters of 1.6 and $2.7 \mathrm{~mm}$, jet exit velocities of $170-1630 \mathrm{~mm} / \mathrm{s}$, jet exit Reynolds numbers of 46-172, characteristic residence times (defined as $2 L_{\mathrm{f}} / u_{\mathrm{o}}$ ) of $40-302 \mathrm{~ms}$, and luminous flame lengths of $15-63 \mathrm{~mm}$.

For convenience, the test numbers have the suffixes $E$ and $P$ to denote ethylene- and propane-fueled flames, respectively. Asterisks are used to denote the two tests completed during flight STS-83. It should be noted that the characteristic residence times of the present flames are large (40-302 ms) compared to most practical applications where characteristic residence times are typically less than $10 \mathrm{~ms}$. As mentioned earlier, present flames were generally relatively close to laminar smoke point conditions with test flames $01 \mathrm{E}^{*}, 03 \mathrm{E}^{*}$, and $01 \mathrm{E}$ actually emitting soot in the period when flame shape observations were made. The remaining flames all contained soot but were not emitting soot.

\section{THEORETICAL METHODS}

The goal of the analysis was to develop a convenient method to help interpret and correlate the present flame shape measurements. A set of easily used equations was sought, along with recommendations for selecting the thermochemical and transport properties appearing in these equations, as opposed to more complete methods that would require numerical solutions on a computer. Thus, the basis for this approach was the simplified analysis of nonbuoyant round laminar jet diffusion flames due to Spalding 
[22]. The following description of the analysis is brief and concentrates on the present application of the approach; see Spalding [22] and Kuo [23] for more details.

The major assumptions of the flame shape analysis of Spalding [22] are as follows: (1) attention is limited to steady, axisymmetric laminar jet diffusion flames burning at constant pressure in still environments; (2) effects of buoyancy and associated changes of potential energy are negligible; (3) the Mach number of the flow is small so that effects of viscous dissipation and changes of kinetic energy can be ignored; (4) the flame has a large aspect ratio so that diffusion of mass (species), momentum, and energy in the streamwise direction is small; (5) for the same reasons, the solution of the governing equations can be approximated by far-field conditions where the details of initial conditions at the jet exit can be replaced by jet invariants for the conservation of mass (elements), momentum, and energy in the integral sense; (6) all chemical reactions occur in a thin flame sheet with fast chemistry so that fuel and oxidant are never simultaneously present at finite concentrations; (7) the diffusivities of mass (of all species), momentum and energy are all equal; (8) all thermophysical and transport properties are constant throughout the flame; and (9) effects of radiation are small. The first three assumptions are justified as conditions of the present experiments. The fourth and fifth assumptions are justified for at least the portion of the present measurements that have large aspect ratios (e.g., present measurements summarized in Table 1 involve flame aspect ratios, $2 L_{f} / w_{\text {MAX }}$, in the range $2-9$, and burner aspect ratios, $L_{\mathrm{f}} / d$, roughly four times larger). The sixth assumption prescribing a thin diffusion flame sheet has a long history of effective application to find the shape of laminar diffusion flames, extending back to the classical work of Burke and Schumann [2]. The remaining assumptions, however, are not satisfied by laminar jet diffusion flames and were only adopted here so that a simple formula for flame shapes could be found, and due to past success of similar approximations for analysis of the shapes of laminar diffusion flames [20-24].

Solution of the governing equations using the present assumptions, after associating the loca- tion of the luminous flame boundary with the location of the thin flame sheet where the stoichiometric mixture fraction is reached, yields the following expression for the luminous flame length $[22,23]$ :

$L_{\mathrm{f}} / d=(3 / 32) R e / Z_{\mathrm{st}}$.

The value of $Z_{\mathrm{st}}$ in Eq. 1 can be found simply as the mass fraction of burner exit fluid (fuel in the present case) in a stoichiometric mixture of burner-exit fluid and ambient fluid (air in the present case); these values are summarized in Table 1 for the present test conditions. The variation of $Z_{\mathrm{st}}$ is not large for combustion of hydrocarbon/air mixtures; thus, while the variation of $Z_{\mathrm{st}}$ is small for present experiments, the values considered are relevant to many practical applications. The corresponding expression for the flame shape, yielding the flame diameter as a function of streamwise distance, is as follows:

$w Z_{\mathrm{st}} / d=3^{1 / 2}\left(z / L_{\mathrm{f}}\right)\left[\left(L_{\mathrm{f}} / z\right)^{1 / 2}-1\right]^{1 / 2}$.

Differentiating Eq. 2, and setting the result equal to zero, provides expressions for the maximum flame diameter and the streamwise distance where this maximum diameter is reached, as follows:

$w_{\text {MAX }} Z_{\text {st }} / d=9 / 16$ at $z / L_{\mathrm{f}}=9 / 16$.

Correlation of the measurements was sought by selecting conditions to find mean transport properties and introducing some empirical parameters to match measurements and predictions. First of all, the equal diffusivity approximation was relaxed by introducing the Schmidt number into Eq. 1 because the flame sheet is mainly affected by mass transport properties represented by the Schmidt number. Transport properties affect Eqs. 1-3 through the Schmidt number and the viscosity used to compute the Reynolds number. It was found that a reasonable correlation of luminous flame lengths could be obtained by approximating these properties by the properties of air at the average of the adiabatic flame temperature and the ambient temperature. This selection seems reasonable because air-like gases dominate the composition of the present flames. The properties needed to find the Schmidt number and the mean gas viscosity were taken from Braun et al. 
[28]. The range of the flame shape correlations was extended to flames having small aspect ratios by introducing a virtual origin at a distance $L_{\mathbf{o}}$ from the jet exit, which is a conventional step for properties like luminous flame lengths. The flame length expression was then fine-tuned by introducing an empirical coefficient, $C_{\mathrm{f}}$, as discussed later. With these changes, Eq. 1 for the luminous flame length becomes:

$\left(L_{\mathrm{f}}-L_{\mathrm{o}}\right) / d=\left(3 C_{\mathrm{f}} / 32\right) \operatorname{ReSc} / Z_{\mathrm{st}}$,

while Eq. 2 for the luminous flame diameter becomes

$w Z_{\mathrm{st}} / d_{\mathrm{s}}=3^{1 / 2} \zeta\left(\zeta^{-1 / 2}-1\right)^{1 / 2}$

where

$\zeta=\left(z-L_{\mathrm{o}}\right) /\left(L_{\mathrm{f}}-L_{\mathrm{o}}\right)$.

Thus, the flame radius properties are only indirectly affected by assumed transport properties, through the computation of the flame length of Eq. 4.

\section{RESULTS AND DISCUSSION}

\section{Flame Appearance}

Ignition conditions were established during ground-based tests at microgravity using a freefall facility and involved fuel flow rates greater than the values used during the present flame tests. Thus, after ignition was confirmed, fuel flow rates were reduced to conditions near but generally smaller than the laminar smoke point fuel flow rates. Exceptions to this practice where tests $01 \mathrm{E}^{*}, 03 \mathrm{E}^{*}$, and $01 \mathrm{E}$, that were soot emitting.

After the fuel flow rate was set, an additional $5-10 \mathrm{~s}$ was required for disturbances to decay away. The flames were then observed during an 80-180 s quasi-steady burning period where flame shapes and colors changed slowly due to the modest variations of oxygen concentrations, pressures and temperatures of the gas within the test chamber, see Urban et al. [27] for typical records of chamber gas properties as a function of time during the experiments. Video records used for the present flame shape measurements were obtained near the start of the quasi-burning period; therefore, the test condi- tions correspond to the nominal conditions summarized in Table 1 within experimental uncertainties.

Typical of many past observations of sootcontaining nonbuoyant laminar jet diffusion flames [8-14], present flame shapes could be grouped into closed-tip and opened-tip configurations, which were observed for fuel flow rates smaller and larger than the laminar smoke point fuel flow rates, respectively. In fact, the tip-opening phenomenon provided a convenient indicator of laminar smoke points for present test conditions because the associated dramatic change of the shape of the flame tip invariably corresponded to the first observations of soot emissions.

Some typical video records of the present closed-tip laminar nonbuoyant jet diffusion flames are illustrated in Fig. 1. The test numbers, corresponding to the test numbers of Table 1, are marked below each image. The flames illustrated include both ethylene- and propane-fueled flames for jet exit diameters of $1.6 \mathrm{~mm}$. The jet exits, which are visible only in the images of tests $02 \mathrm{E}, 03 \mathrm{E}, 16 \mathrm{E}$, and $17 \mathrm{E}$, are on the same side of each image as the test number. As noted earlier, fixed camera settings imply that images of some strongly-luminous flames are overexposed. Thus, while the images provide a general indication of regions of the flames that have different colors, they do not provide an accurate representation of actual flame colors. In spite of this limitation, however, luminous flame shapes and corresponding flame shape parameters (e.g., luminous flame lengths and diameters) can still be identified from the video images. In addition to the brightly luminous region caused by the presence of glowing soot velocities, blue luminosity can be seen near the jet exit and just beyond the edge of the brightly luminous region, particularly near the base of the flame. The blue region was never resolved clearly, however, and was not visible at all near the flame tip due to the presence of the brightly luminous region. Finally, as the laminar smoke point fuel flow rate was approached, the flames tended to become blunt as a precursor to the tip-opening phenomena; thus, the images of tests $02 \mathrm{E}, 16 \mathrm{E}$, and $18 \mathrm{P}$ are typical of blunt closed-tip flames.

The present measurements of flame shapes 
were based on the boundary of the brightly luminous region caused by visible radiation from soot because this was the most obvious indication of luminous fiame shape. The stoichiometric flame sheet (the flame sheet based on the location of the stoichiometric mixture fraction) also is of great interest but this condition could not be resolved, as already discussed. Thus, the relationship between the luminous flame boundaries and the position of the stoichiometric flame sheet is important for interpreting the present measurements. Soot concentration and temperature records suggest that the present luminous flame boundaries lie just inside the stoichiometric flame sheet along the sides of the flame, not too near the flame tip; see Urban et al. [27] for some typical examples. The same evidence suggests that the present luminous flame boundaries extend beyond the stoichiometric flame sheet in the streamwise direction near the flame tip, due to soot burnout in the lean portions of the flames because present test conditions were close to laminar smoke points. Unfortunately, the extent of the streamwise overlap cannot be quantified directly because local mixture fractions are not known for the present flames. As discussed earlier, past measurements in laminar jet diffusion flames suggest that the luminous flame length might be as much as twice the flame length based on the location of the stoichiometric conditions along the axis for conditions near the laminar smoke point [15-18]. Thus, in order to help quantify differences between luminous and stoichiometric flame lengths, the flame lengths of both soot-containing and soot-free nonbuoyant laminar jet diffusion flames for similar burner and buoyancy conditions will be compared in the following.

Some typical video records of opened-tip nonbuoyant laminar jet diffusion flames are illustrated in Fig. 2. The identification of test conditions and the location of the burner exit are the same as Fig. 1. The flames illustrated include ethylene-fueled flames for a jet exit diameter of $2.7 \mathrm{~mm}$ and propane-fueled flames for a jet exit diameter of $1.6 \mathrm{~mm}$. The dramatic difference between the shape of the tips of closed- and opened-tipped flames is clearly evident by comparing the flame images of Figs. 1 and 2. Measurements of the structure of opened-tipped flames show that soot is mainly confined to an annular region, and that little soot is present along the flame axis [27]. Thus, soot luminosity from the annular-soot containing region, combined with small levels of soot luminosity along the axis, is responsible for the blunt or even cusp-like luminous shape of the tip of these flames when viewed from the side as projections. The flames illustrated in Fig. 2 have fuel flow rates slightly smaller than the laminar smoke point fuel flow rates. Video images of opened-tip flames that are emitting soot, tests $01 \mathrm{E}^{*}$ and $03 \mathrm{E}^{*}$, appear in Urban et al. [27]; however, they are qualitatively similar to the opened-tip flames illustrated in Fig. 2.

\section{Flame Lengths}

The luminous flame length of laminar jet diffusion flames is a widely reported property that is used to both characterize flame shapes and to summarize soot emission properties (as laminar smoke point flame lengths). The luminous flame lengths reported here are the streamwise distances between the burner exit and the farthest downstream plane normal to the flame axis that contacts a luminous region of the flame [either along the axis for closed-tip (non-sootemitting or nonsooting) flames or at the annular soot layer for opened-tip (nonsooting and sootemitting or sooting) flames]. It is well known that $L_{f} / d$ can be correlated as a linear function of the jet exit Reynolds numbers, $R e$, for buoyant laminar jet diffusion flames for a given fuel and ambient environment, however, each fuel has its own individual correlation curve [19-24]. Thus, the performance of similar correlations will be considered for the present nonbuoyant laminar jet diffusion flames, based on the simple classical theory of Spalding [22] as discussed earlier, seeking a general correlation capable of treating various fuels, burner diameters, and ambient environments (pressures, temperatures, oxygen concentrations, etc.).

Measured and predicted luminous flame lengths of the present nonbuoyant laminar jet diffusion flames are illustrated in Fig. 3. These results are presented as suggested by the modified Spalding [22] analysis, Eq. 4 , with $\left(L_{f}-\right.$ $\left.L_{\mathrm{o}}\right) / d$ plotted as a function of $\operatorname{Re} S c / Z_{\mathrm{st}}$. Measured luminous flame lengths are shown for all 


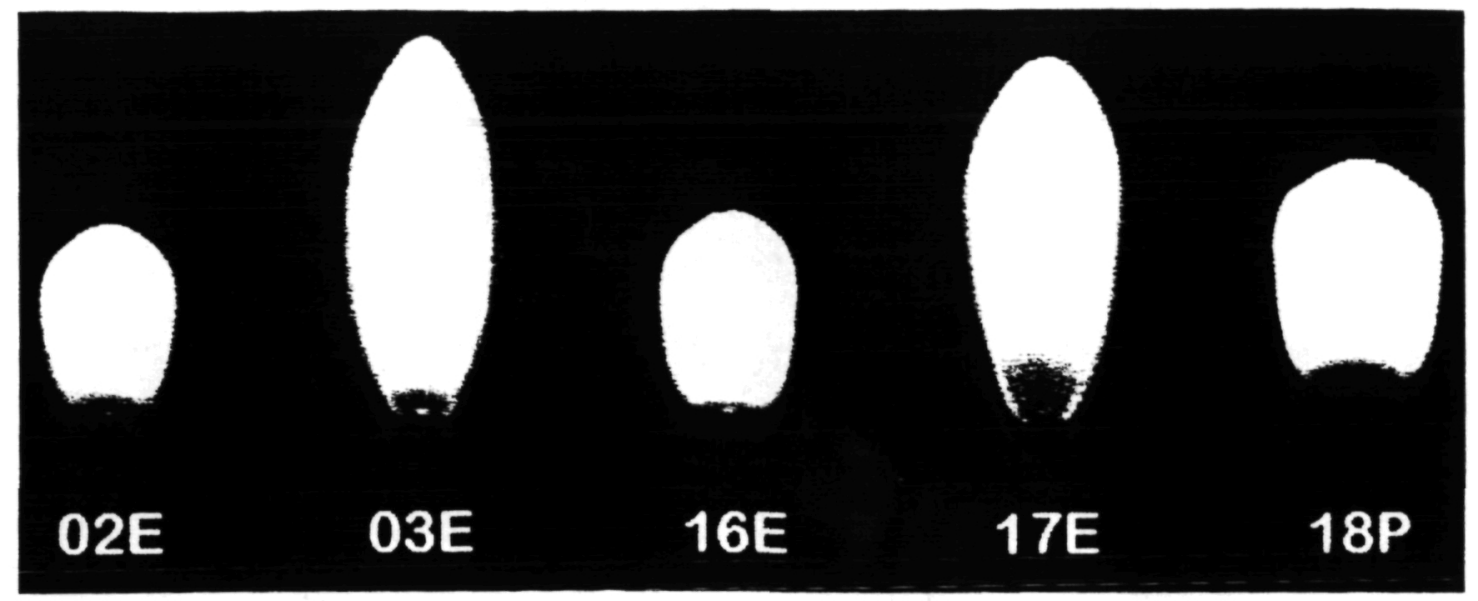

Fig. 1. Video images of typical closed-tip luminous hydrocarbon/air laminar jet diffusion flames (Tests 02E, 03E, 16E, 17E, and $18 \mathrm{P})$.

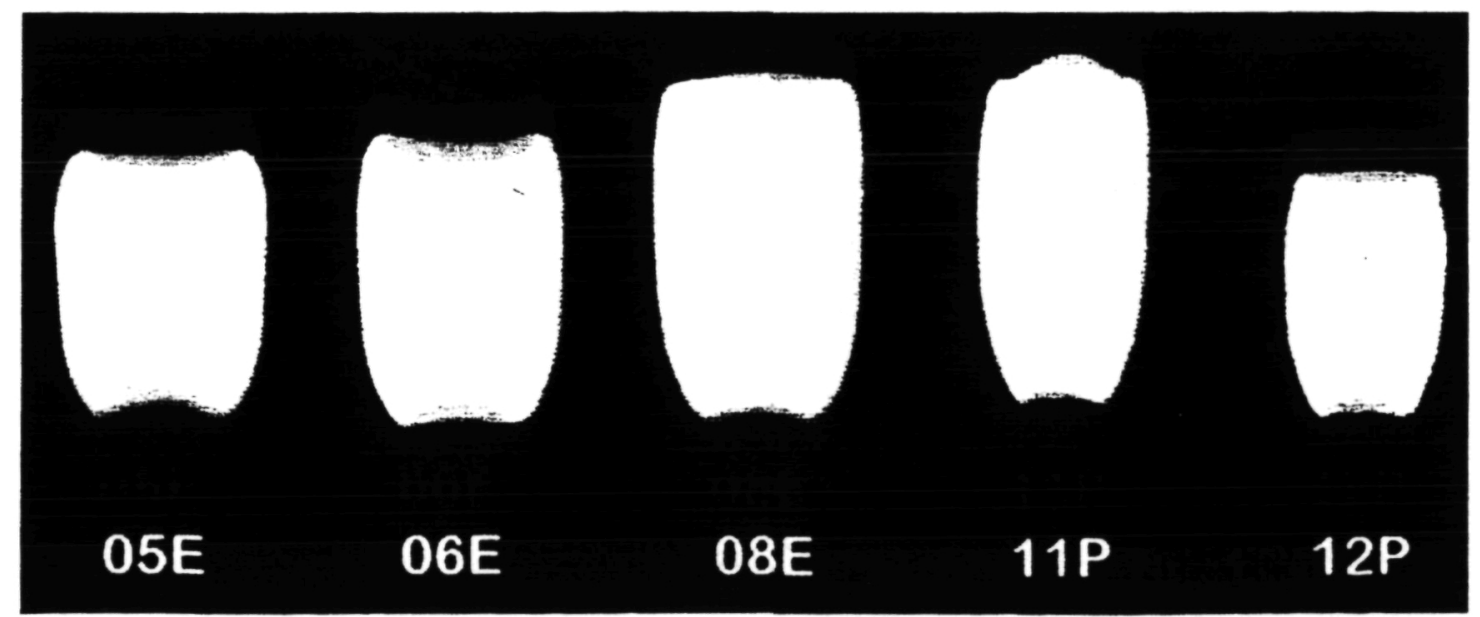

Fig. 2. Video images of typical opened-tip luminous hydrocarbon/air laminar jet diffusion flames (Tests 05E, 06E, 08E, 11 P. and $12 \mathrm{P})$. 


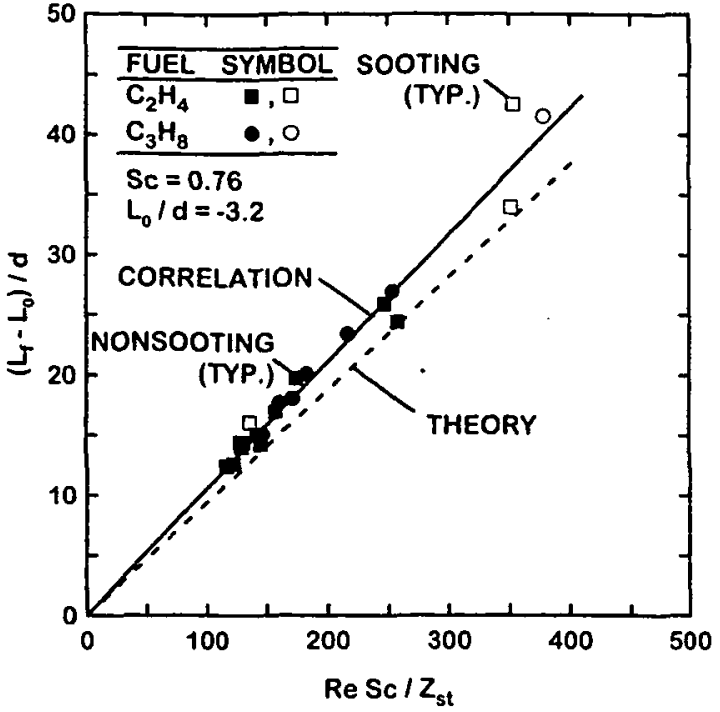

Fig. 3. Measured and predicted luminous flame lengths of nonbuoyant hydrocarbon/air laminar jet diffusion flames as a function of $\operatorname{ReSc} / Z_{\mathrm{st}}$; measurements from present spacebased experiments.

the test conditions summarized in Table 1 , with non-sooting and sooting flames denoted by closed and open symbols, respectively. The values of $Z_{\mathrm{st}}$ used for the ethylene-fueled and propane-fueled flames are summarized in Table 1; other properties were taken from Braun et al. [28]. Values of Sc were based on the properties of air at the mean temperature of the flames; these values do not vary significantly over the present test range so that a mean value of $S c=$ 0.76 was adopted for all the predictions. The value of $\mu$ used to find the $R e$ in Eq. 4 was also based on the properties of air at the mean flame temperature. A virtual origin at $L_{\mathrm{o}} / d=-3.2$ was selected so that the fit of present data passed through the origin of the plot. This type of initial flame displacement seems quite reasonable because the flames generally attached somewhat below the jet exit; see Figs. 1 and 2 . Furthermore, this empirical displacement of the origin should hold for other flames at similar conditions. In addition, this displacement of the virtual origin, $L_{\mathrm{v}} / d=-3.2$, is relatively small compared to the present normalized flame lengths ( $L_{f} d d$ in the range $9-39$ ), which is typical of conventional use of virtual origins to extend large aspect ratio correlations to modest aspect ratio conditions. Finally, plots of Eq. 4 for the $C_{f}$ $=1.00$ (denoted theory) and a best-fit correlation for the present data for $C_{\mathrm{f}}=1.13$ (denoted correlation) are also shown on the figures for comparison with present measurements. For convenience, values of the virtual origin and $C_{\mathrm{f}}$ for all the flame length correlations considered here are summarized in Table 2.

The unprecedented steadiness of the present nonbuoyant laminar jet diffusion flames at microgravity minimized measurement uncertainties and yielded the remarkably unscattered correlation of luminous flame lengths illustrated in Fig. 3. The results for closed-tip and openedtip flames are illustrated but there is little to choose between the two because tip opening does not modify luminous flame lengths significantly. This is somewhat surprising because the end of luminosity in soot-emitting flames is caused by soot particles cooling below a level where they can be observed rather than by soot burnout which is the case for the other flames. Nevertheless, these different mechanisms for

TABLE 2

Summary of Flame Length Correlations

\begin{tabular}{|c|c|c|c|}
\hline Flame system & Source & $L d d$ & $C_{f}^{b}$ \\
\hline $\begin{array}{l}\text { Space-based, soot-containing } \\
\text { and nonbuoyant }\end{array}$ & Present study & -3.2 & 1.13 \\
\hline $\begin{array}{l}\mathrm{KC}-135 \text {, soot-containing and } \\
\text { nonbuoyant }\end{array}$ & Sunderland et al. $[14]^{a}$ & 0.4 & 0.80 \\
\hline $\begin{array}{l}\text { 1-g, soot-containing and } \\
\text { buoyant }\end{array}$ & Urban et al. [26] & -1.0 & 0.57 \\
\hline $\begin{array}{l}\text { Drop tower, soot-free and } \\
\text { nonbuoyant }\end{array}$ & Sunderland et al. [13] & 2.7 & 0.56 \\
\hline
\end{tabular}

${ }^{a}$ Previously unpublished measurements obtained during the course of the cited study.

"The slope of the flame length correlations in Figs. 3 and 4 can be found hy multiplying the $C_{1}$ by 3/32, following Eq. 4. 


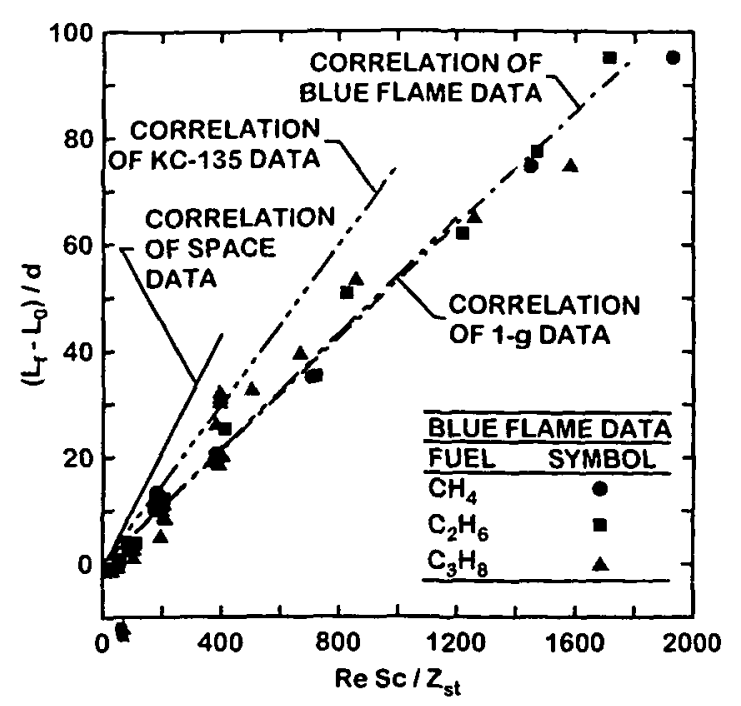

Fig. 4. Luminous flame lengths of hydrocarbon/air laminar jet diffusion flames as a function of $R e S c / Z_{\text {st }}$; correlation of measurements of soot-free (blue) flames from Sunderland et al. [13], correlation of measurements of KC-135 flames obtained during the study reported by Sunderland et al. [14], measurements (symbols) and correlation of $1-\mathrm{g}$ flames reported by Urban et al. [26] and correlation of measurements of the present space-based flames. Note that the various correlations are terminated at the upper end of their corresponding data range.

ending flame luminosity do not have a large effect, with the luminous flame length correlations of the nonsooting and sooting flames being essentially the same; therefore, both sets of data are included in the present correlation according to Eq. 4.

The present selections of mean transport properties in Eq. 4 yield results that are in surprisingly good agreement with the measurements. In particular, the best fit value of $C_{\mathrm{f}}$ is only $13 \%$ larger than unity. This behavior is somewhat fortuitous, however, because the luminous flame length corresponds to the end of the soot-containing region at near laminar smoke point conditions, which generally is downstream from the position of the stoichiometric flame sheet, as discussed earlier.

Several additional experimental determinations of luminous flame lengths are plotted along with the present measurements in Fig. 4 in order to gain insight about effects of unsteadiness, buoyancy, and soot luminosity on luminous flame lengths. In order to provide a unified basis for comparison, all these results are based on experiments with laminar jet diffusion flames in still air having burner exit and test chamber configurations similar to the present space-based experiments and are plotted according to the Spalding [22] analysis. The resulting best fit values of $L_{\mathrm{o}} / d$ and $C_{\mathrm{f}}$ for each of these sets of data are summarized in Table 2. All the measurements illustrated in Fig. 4 correlated quite nicely according to Eq. 4 , and have relatively small virtual origins as summarized in Table 2. On the other hand, flame lengths differ considerably for the various test conditions with present space-based flames clearly longer than the rest; this behavior is quantified by the values of $C_{\mathrm{f}}$ summarized in Table 2. Reasons for this behavior are discussed next.

The results closest to the present measurements in Fig. 4 are based on a correlation of earlier measurements of luminous flame lengths of nonbuoyant soot-containing flames for test conditions similar to the present measurements except carried out at low gravity using the KC-135 aircraft facility [14]. These low-gravity tests were completed to assist the development of the present space-based microgravity experiments so that burner properties were the same and laminar smoke point conditions were approached. Finally, available times at low gravity were relatively long, roughly $20 \mathrm{~s}$, to minimize potential effects of unsteadiness. Thus, these test conditions provided reasonably close simulations of the present space-based microgravity experiments. Nevertheless, the best-fit correlations of the two sets of measurements indicate that the space-based flames are consistently longer, by roughly $40 \%$, than the flames observed using the KC-135 facility. These differences are attributed to well-known effects of disturbances of the gravitational field when using aircraft facilities ( $g$-jitter) with enhanced mixing due to these disturbances tending to reduce luminous flame lengths.

The results next closest to the present measurements in Fig. 4 are based on a correlation of earlier measurements of luminous flame lengths of buoyant soot-containing flames for test conditions similar to the present experiments except carried out at normal gravity [26]. These tests were completed to assist development of the present space-based experiments so that burner properties were the same and laminar 
smoke point conditions were approached. Similar to other observations of buoyant soot-containing laminar jet diffusion flames [19], these flames provide the linear correlation between luminous flame lengths and fuel flow rates mentioned earlier. Nevertheless, the present space-based flames are roughly twice as long as the buoyant flames, due to the absence of enhanced mixing caused by convection effects resulting from buoyant motion.

The last series of luminous flame lengths illustrated in Fig. 4 are due to Sunderland et al. [13] and yield a laminar flame length correlation very similar to the results for buoyant flames but for very different reasons. The luminous flame length measurements of Sunderland et al. [13] involved nonbuoyant soot-free (blue) methane-, ethane-, and propane-fueled round laminar jet diffusion flames burning in still air at microgravity using a $2.2 \mathrm{~s}$ drop tower facility. The burner properties were similar to the present spacebased experiments. As noted earlier, burner diameters, fuel flow rates and ambient pressures were manipulated in order to eliminate the presence of soot so that blue flames were observed whose location could be associated with the position of the stoichiometric flame sheet. These same tactics also reduced characteristic flame residence times to minimize effects of transient flame development. The luminous flame lengths of Sunderland et al. [13] exhibit somewhat greater scatter than the present space-based laminar flame lengths (see Fig. 3) when correlated according to Eq. 4; this behavior is probably due to ignition disturbances and flame development effects caused by the limited available test time at microgravity. Nevertheless, a reasonably good correlation between predictions and measurements is achieved. (Note that Sunderland et al. [13] also compare their luminous flame lengths to predictions from Burke and Schumann [2], Roper [21] and Klajn and Oppenheim [24].). The luminous flame lengths of the present space-based flames, however, are roughly twice as long as the nonbuoyant soot-free flames; this difference is felt to be mainly due to the different locations of the luminous flame length and the stoichiometric flame sheet as the laminar smoke point is approached, as discussed earlier. Notably, Sunderland and co-workers $[15,16]$ find similar differences between these two locations along the axis of their weakly-buoyant flames as the laminar smoke point is approached for similar fuels, which tends to support this conclusion.

\section{Flame Diameters}

The normalized maximum flame diameter, $w_{\text {MAX }} Z_{\mathrm{st}} / d$, is simply a constant value, 0.563 , according to Eq. 3. This implies that maximum flame diameters for nonbuoyant laminar jet diffusion flames burning in still air are only functions of the jet exit diameter and the stoichiometry, and are remarkably independent of parameters associated with fuel flow rates and transport properties, such as $R e$ and $S c$. Another parameter of interest is the flame diameter at the mid-point of the flame, $\zeta=1 / 2$. This parameter can be readily found from Eq. 5 , as follows:

$w_{1 / 2} Z_{\mathrm{s}} / d=0.557$ at $\zeta=1 / 2$.

Thus, $w_{\operatorname{MAX}}$ and $w_{1 / 2}$ are essentially the same, mainly because the streamwise locations of these positions are not very different. Thus, flame diameter results will be presented in the following as $w_{\text {MAX }}$ in order to avoid cluttering the plots.

As noted earlier, the blue stoichiometric boundaries could not be identified for the present test flames due to the adjustment limitations of the color video camera. Thus, the maximum luminous flame diameter was found from the luminous boundaries of the sootcontaining region, similar to the present luminous flame lengths. Measurements of radial temperature distributions in the vicinity of the maximum flame diameter (see Urban et al. [27] for some typical examples) suggest that the stoichiometric flame sheet was just outside these boundaries.

Measured and predicted normalized maximum flame diameters, $w_{\mathrm{MAX}} Z_{\mathrm{sl}} / d$, are plotted as a function of normalized luminous flame lengths in Fig. 5. Present measurements for both ethylene- and propane-fueled flames are shown. The predicted correlation of Eq. 3, along with the best-fit values of the measurements for the ethylene- and propane-fueled flames are also shown on the plot. 


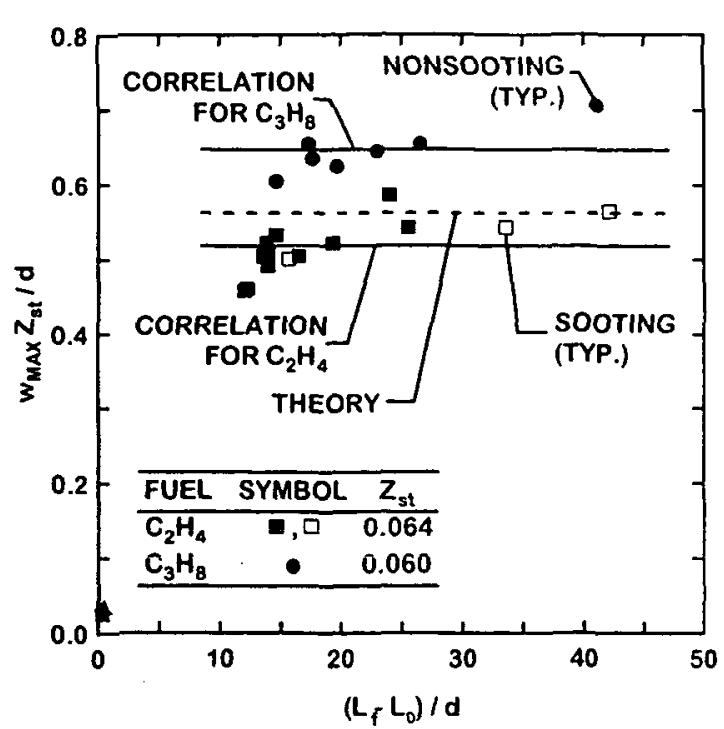

Fig. 5. Measured and predicted luminous flame diameters of nonbuoyant hydrocarbon/air laminar jet diffusion flames; measurements from present space-based experiments.

The experimental results illustrated in Fig. 5 are in remarkably good agreement with the predictions. There is a slight tendency for $w_{\mathrm{MAX}}$ to increase with increasing luminous flame lengths but present flames are relatively long, $\left(L_{f}-L_{\mathrm{o}}\right) / d>10$, and maximum flame diameters are essentially independent of flame length, agreeing with the trend predicted by the theory. The measured normalized maximum luminous flame diameters are slightly scattered about the prediction, with the best fit values of 0.518 and 0.647 for the ethylene- and propanefueled flames, respectively, compared with the theoretical prediction of 0.563 . The locations of the normalized maximum flame diameters for closed-tip flames also correspond reasonably well to estimates from Eq. 3, i.e., they are observed at roughly the mid-point of the flame; see Test 03E illustrated in Fig. 1. The maximum flame diameters for the blunt-tipped and opened-tip flames are observed beyond the midpoint toward the tip of the flames, see the flames illustrated in Fig. 2. This may help explain why the average values of $w_{\mathrm{MAX}} Z_{\mathrm{sl}} / d$ for the present propane-fueled flames is larger than the value of this parameter for the ethylenefueled flames, because most of the propanefueled flames have the opened-tip configuration; see Fig. 2. Thus, based on the rather effective predictions of flame widths from Eq. 2, it becomes clear that the larger jet exit diameter is mainly responsible for the larger flame diameters, and smaller flame aspect ratios, for the luminous flame boundaries of Tests $05 \mathrm{E}, 06 \mathrm{E}$, and $08 \mathrm{E}$ illustrated in Fig. 2 (see Table 1). Finally, the effectiveness of the predictions of Eq. 3 are somewhat startling because the results cannot be fitted to the measurements by appropriately selecting a condition to estimate mean transport properties in the same manner as the luminous flame length correlation.

\section{Flame Shapes}

Present predicted and measured luminous flame shapes are compared in the following as a final step in the evaluation of the effectiveness of Eq. 4 due to Spalding [22] for correlating luminous flame shape data. This comparison is illustrated in Fig. 6 for some typical closed-tip flames, with the radial position of the luminous flame boundary plotted directly as a function of streamwise distance. The predictions shown in the figure were computed as described in connection with Figs. 3-5, using the best fit values of $C_{\mathrm{f}}$ and $L_{\mathrm{o}} / d$ given in Table 2 . The agreement between measurements and predictions is seen to be excellent for Tests $03 \mathrm{E}$ and $16 \mathrm{E}$ in spite of the complexity of the flame processes that define the location of the luminous flame boundaries and the simplicity of the Spalding [22] theory. The comparison between measurements and predictions is not quite as good for Test 18P in the region near the flame tip, however, because this is a relatively blunt closed-tip flame as discussed in connection with Fig. 5.

Measured and predicted luminous flame boundaries for opened-tip ethylene- and propane-fueled flames are plotted in Figs. 7 and 8 , respectively. It is evident that the flame length predictions remain reasonably good for these opened-tip flames but the shapes of the tips of the flames are not predicted very well. Such behavior is certainly not surprising because the theory does not consider processes of flame extinction along the axis and the formation of an annular soot layer. Nevertheless, the fortuitous qualitative agreement between measurements and predictions should still be helpful for estimating the flame-containing region of non- 

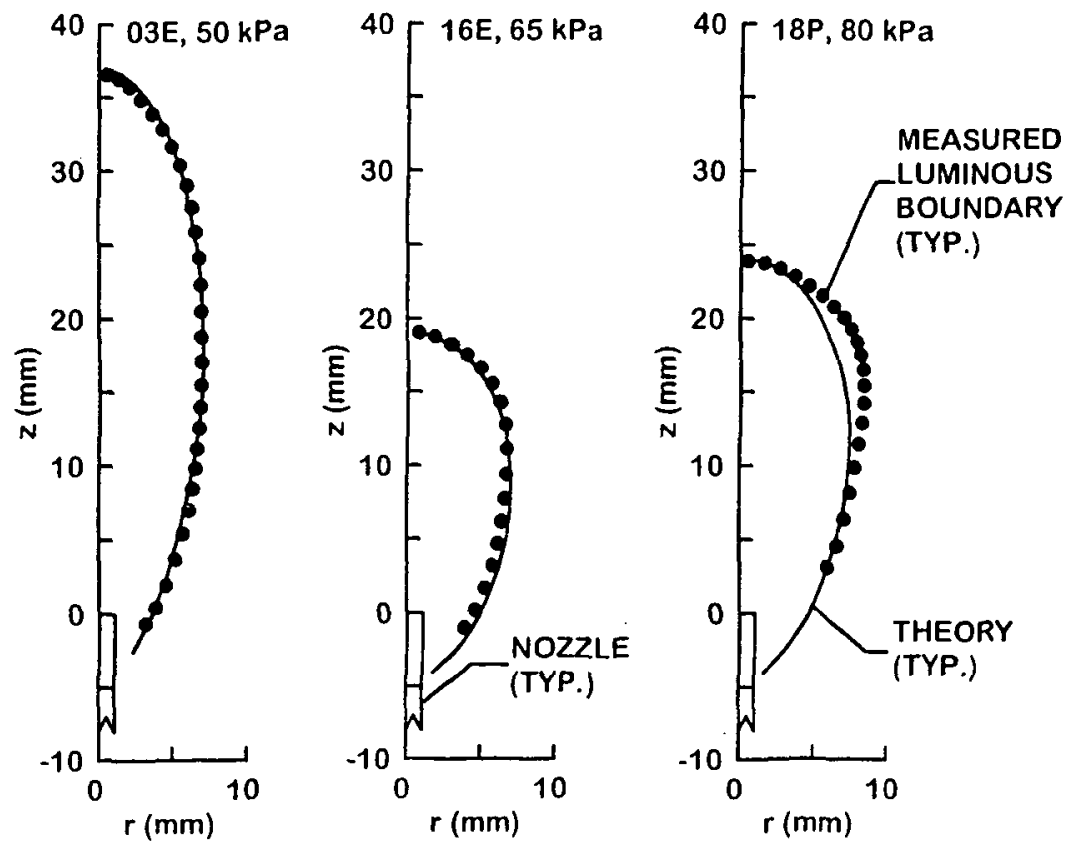

Fig. 6. Measured and predicted luminous flame shapes for typical closed-tip nonbuoyant hydrocarbon/air laminar jet diffusion flames; measurements from present space-based experiments (Tests $03 \mathrm{E}, 16 \mathrm{E}$, and 18P).

buoyant laminar jet diffusion flames when imaging systems are designed for nonintrusive measurements of flame properties, if this finding proves to be robust for reasonable ranges of test conditions.

Measured and predicted luminous flame shapes for the present nonbuoyant laminar jet diffusion flames are plotted according to the normalized variables of Eq. 4 in Figs. 9 and 10 for selected closed-tip and opened-tip flames, respectively. Predictions shown on these plots were obtained as described in connection with Figs. 3 and 5. As expected from the results discussed thus far, the agreement between mea-
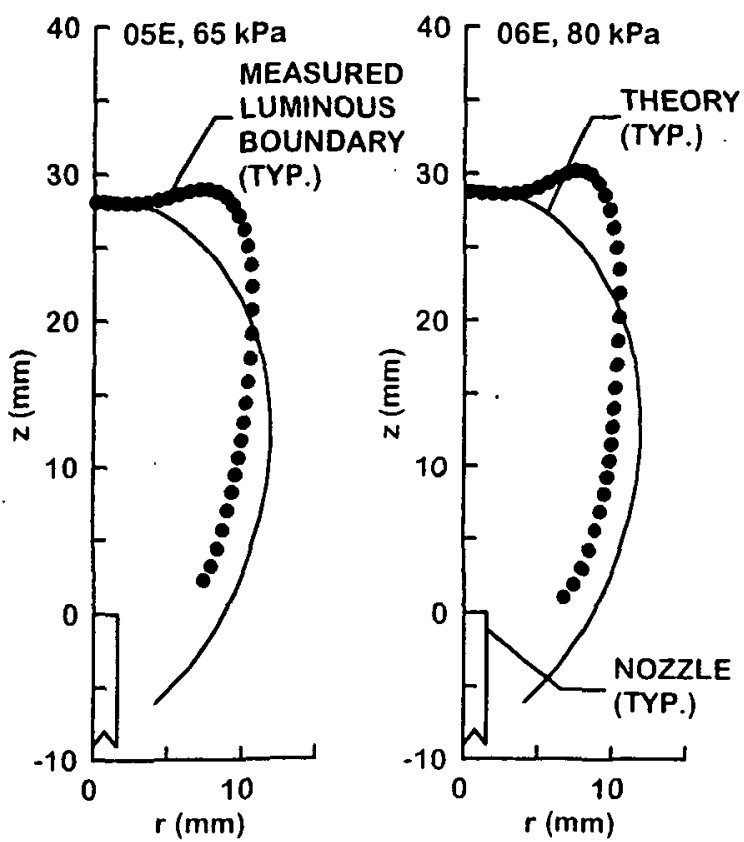

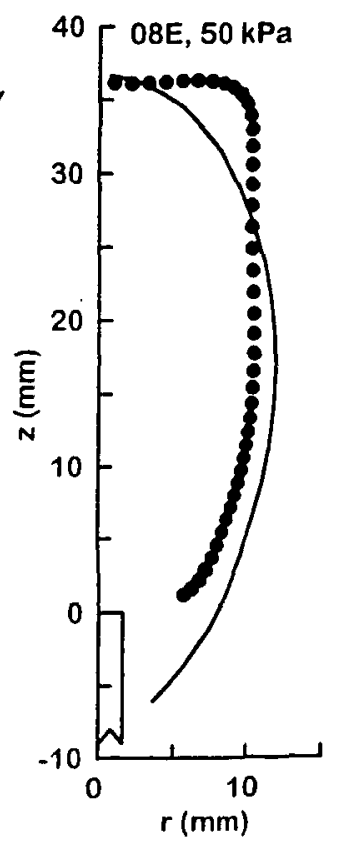

Fig. 7. Measured and predicted luminous flame shapes for typical opened-tip nonbuoyant ethylene/air laminar jet diffusion flames; measurements from present space-based experiments (Tests 05E, 06E, and 08E). 


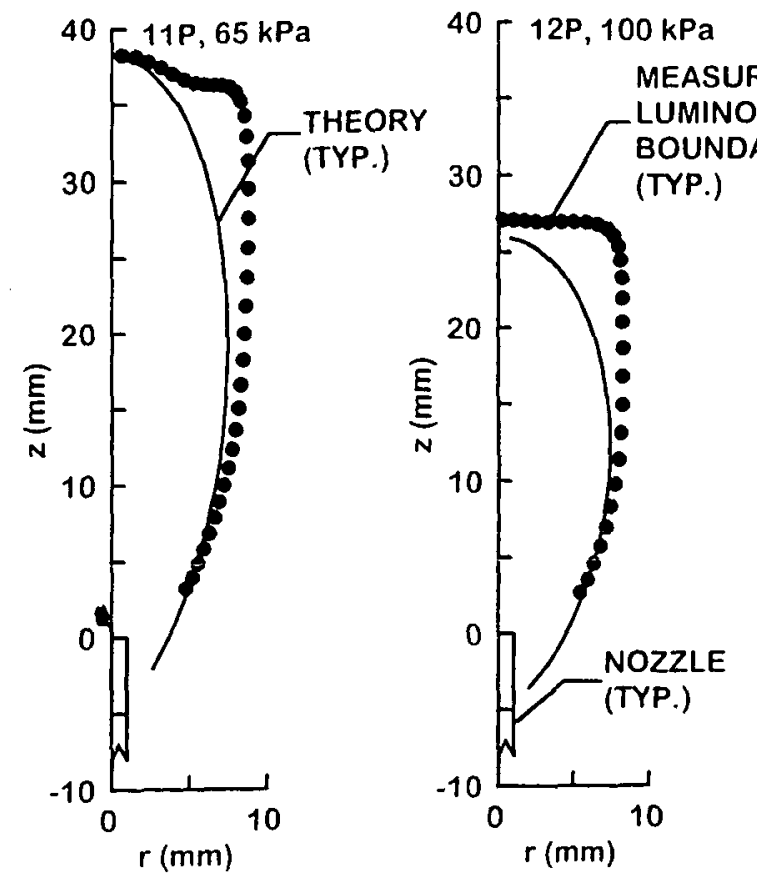

surements and predictions is excellent for the closed-tip flames in Fig. 9, except for the blunttipped flames that are seen as the laminar smoke point fuel flow rate is approached. The opened-tip luminous flame shapes are not predicted as well, with significant discrepancies

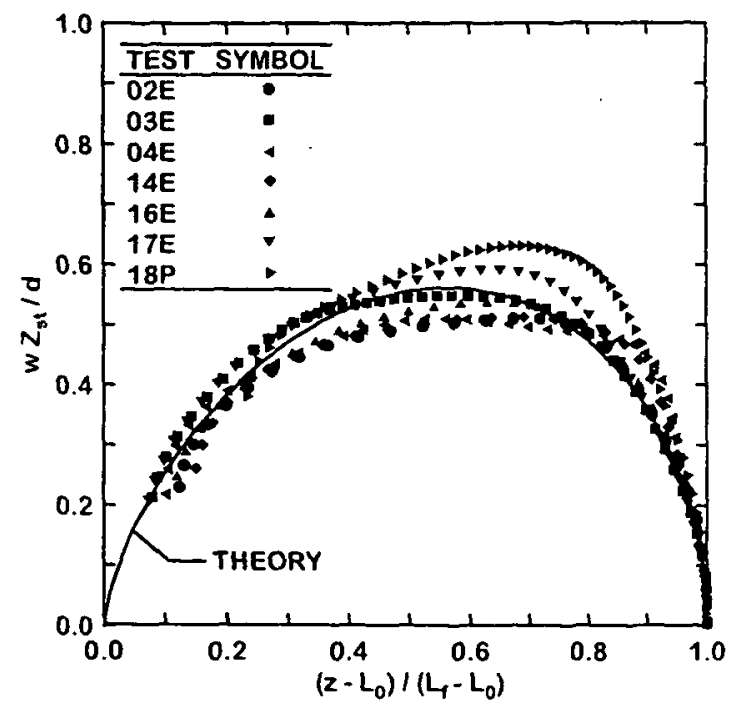

Fig. 9. Measured and predicted normalized luminous flame shapes for closed-tip nonbuoyant hydrocarbon/air laminar jet diffusion fiames; measurements from present spacebased experiments.

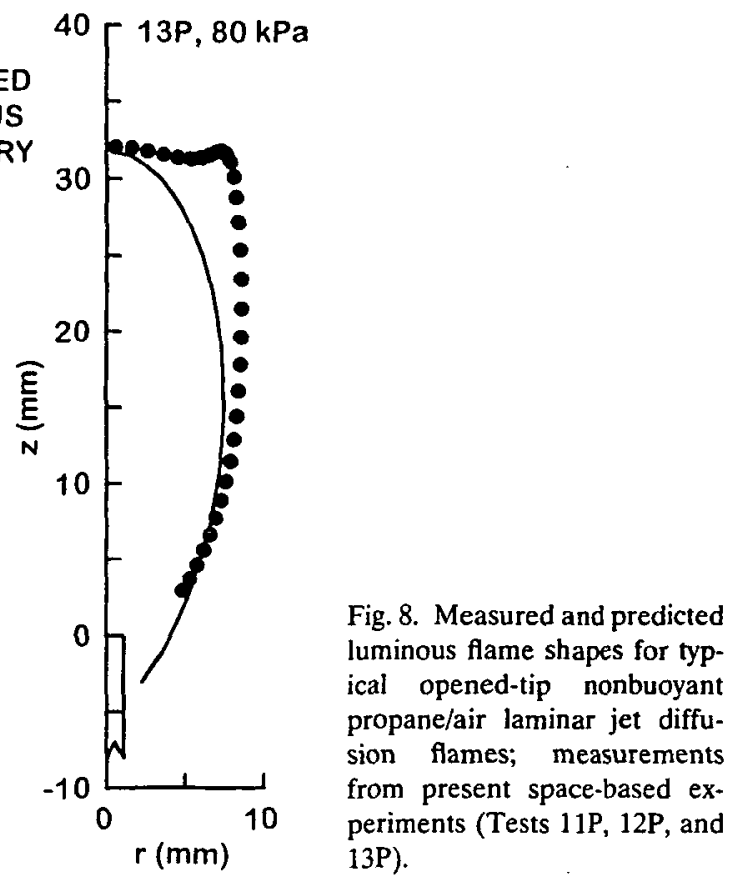

observed between measurements and predictions as the flame tip is approached. In addition, the tendency for opened-tip flames to be broadest near the flame tip, as opposed to the midpoint as indicated by theory, is evident. Nevertheless, the qualitative agreement between

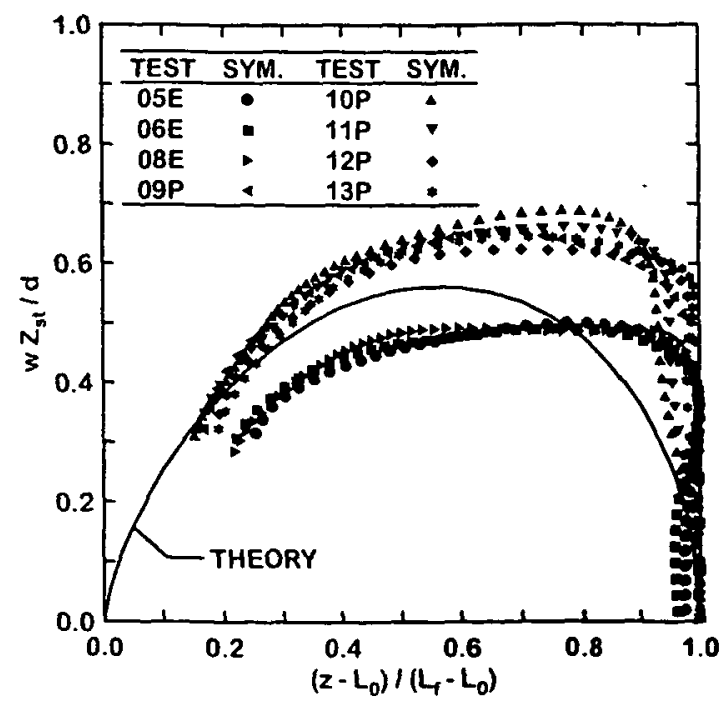

Fig. 10. Measured and predicted normalized luminous flame shapes for opened-tip nonbuoyant hydrocarbon/air laminar jet diffusion flames; measurements from present space-based experiments. 
measurements and predictions, even for opened-tip flames, is quite good considering the simplicity of the model.

\section{CONCLUSIONS}

The luminous flame shapes of steady, nonbuoyant, round laminar jet diffusion flames were studied at microgravity during long-term tests carried out in an orbiting space shuttle. Test conditions involved ethylene- and propane-fueled flames burning in still air at ambient temperatures of $300 \mathrm{~K}$, ambient pressures of 35-130 $\mathrm{kPa}$, initial jet diameters of 1.6 and $2.7 \mathrm{~mm}$, and jet exit Reynolds numbers of $45-170$ to yield luminous flame lengths of $15-63 \mathrm{~mm}$. These test conditions involved soot-containing luminous flames near laminar smoke point conditions, and included both nonsooting and sooting flames. The new measurements were used to evaluate predictions of luminous flame shapes based on the simple classical theory of nonbuoyant laminar jet diffusion flames due to Spalding [22]. The major conclusions of the study are as follows:

1. The present soot-containing luminous flames had larger luminous flame lengths than earlier ground-based observations: $40 \%$ larger than the luminous flame lengths of sootcontaining nonbuoyant flames observed using an aircraft (KC-135) facility due to reduced effects of gravitational disturbances ( $g$-jitter), roughly twice as large as the luminous flame lengths of soot-containing buoyant flames at normal gravity due to the absence of effects of buoyant mixing, and roughly twice as large as the luminous flame lengths of soot-free nonbuoyant flames observed by Sunderland et al. [13] using drop tower facilities due to the presence of soot luminosity and possible reduced effects of unsteadiness.

2. Similar to earlier observations of soot-containing nonbuoyant laminar jet diffusion flames [7-12, 14], present luminous flame shapes could be grouped into closed-tip and opened-tip configurations, which were observed for fuel flow rates smaller and larger than the laminar smoke point fuel flow rate, respectively. Blunt-tipped flames were also observed as fuel flow rates approached the tip-opening condition.

3. The simplified theoretical analysis of nonbuoyant laminar jet diffusion flames due to Spalding [22] yielded excellent correlations of the luminous flame shapes of closed-tip soot-containing and soot-free flames upon adjusting an empirical flame length parameter to account for the fact that flame luminosity ends at the location of soot consumption and at the location of the stoichiometric flame sheet along the axis of soot-containing and soot-free flames, respectively. Nevertheless, the slopes of the flame length correlations in Fig. 4 differed by roughly a factor of 2 for nonbuoyant soot-free (blue) and sootcontaining (near the laminar smoke point limit) flames. This difference is consistent, however, with the ratios between luminous flame lengths and stoichiometric lengths for soot-containing flames reported previously [15-18].

4. Remarkably, the simplified theoretical analysis of nonbuoyant laminar jet diffusion flames due to Spalding [22] fortuitously still yields reasonably good predictions of luminous flame shapes for soot-containing nonbuoyant opened-tip flames as well as for conventional buoyant flames, after appropriate selections of empirical flame length parameters. Thus, taken together, the simple formulation of Eq. 4 exhibits encouraging potential to correlate the luminous flame boundaries of laminar jet diffusion flames that should be useful for designing imaging systems for nonintrusive measurements of flame properties.

5. Based on the present correlations of luminous flame boundaries for nonbuoyant laminar jet diffusion flames, luminous flame lengths increase linearly with fuel flow rate but are relatively independent of jet exit diameter and pressure, while maximum luminous flame diameters increase linearly with jet exit diameter but are relatively independent of fuel flow rate and pressure. Both dimensions, however, are proportional to the stoichiometric mixture fraction, although this parameter was not varied sufficiently during the present experiments to test predictions of this trend. 
The correlation of Eq. 4 from Spalding [22] should be used with caution outside the present test range. Additional experiments are needed to evaluate this expression during long-term space-based tests at microgravity, emphasizing evaluation of effects of approach to the laminar smoke point and the relationship between the locations of the luminous flame boundaries due to the presence of soot and the location of the stoichiometric flame sheet.

This research was supported by NASA grant nos. NAG3-1245 and NAG3-2048 under the overall technical management of Howard $B$. Ross of the NASA Lewis Research Center. The authors would like to acknowledge the contributions of $R$. Hager, A. Over, R. Chucksa, and their associates at NASA LeRC to the development and operation of the test apparatus; to G. T. Linteris, J. E. Voss, and $R$. Crouch of the NASA Johnson Space Center who carried out the assembly of the test apparatus and the execution of the experiments on orbit; and to Z. Dai of The University of Michigan who helped with the collection of the data.

\section{REFERENCES}

1. Bilger, R. W., Prog. Energy Combust. Sci. 1:87 (1976).

2. Burke, S. P., and Schumann, T. E. W., Ind. Eng. Chem. 20:998 (1928).

3. Law, C. K., and Faeth, G. M., Prog. Energy Combust. Sci. 20:65 (1994).

4. Cochran, T. H., and Masica, W. J., Thireenth Symposium (Intemational) on Combustion, The Combustion Institute, Pittsburgh, 1970, p. 821.

5. Haggard, J. B., Jr., and Cochran, T. H., Combust. Sci. Tech. 5:291 (1972).

6. Edelman, R. B., Fortune, O. F., Weilerstein, G., Cochran, T. H., and Haggard, J. B., Jr., Fourteenth Symposium (Intemational) on Combustion, The Combustion Institute, Pittsburgh, 1972, p. 399.

7. Edelman, R. B., and Bahadori, M. Y., Acta Astronautica 13:681 (1986).

8. Bahadori, M. Y., Edelman, R. B., Stocker, D. P., and Olson, S. L., ALAA J. 28:236 (1990).
9. Bahadori, M. Y., Stocker, D. P., and Edelman, R. B., AIAA Paper No. 90-0691, 1990.

10. Bahadori, M. Y., Edelman, R. B., Sotos, R. G., and Stocker, D. P., AIAA Paper No. 91-0719, 1991.

11. Bahadori, M. Y., Edelman, R. B., Stocker, D. P., Sotos, R. G., and Vaughan, D. F., AIAA Paper No. 92-0243, 1992.

12. Bahadori, M. Y., Stocker, D. P., Vaughan, D. F., Zhou, L., and Edelman, R. B., in Modem Developments in Energy, Combustion and Spectroscopy (F. A. Williams et al., eds.), Pergamon, New York, 1993, Chapt. 4.

13. Sunderland, P. B., Mendelson, B. J., Yuan, Z.-G., and Urban, D. L., Combust. Flame 116:376-386 (1998).

14. Sunderland, P. B., Mortazavi, S., Faeth, G. M., and Urban, D. L., Combust. Flame 96:97 (1994).

15. Sunderland, P. B., Köylü, Ü. Ö., and Faeth, G. M., Combust. Flame 100:310 (1995).

16. Sunderland, P. B., Ph.D. thesis, The University of Michigan, Ann Arbor, Michigan, 1995.

17. Mitchell, R. E., Sarofim, A. F., and Clomburg, L. A., Combust. Flame 37:227 (1980).

18. Saito, K., Williams, F. A., and Gordon, A. S., Combust. Sci. Tech. 47:117 (1986).

19. Schug, K. P., Manheimer-Timnat, Y., Yaccarino, P., and Glassman, I., Combust. Sci. Tech. 22:235 (1980).

20. Jost, W., Explosion and Combustion Processes in Gases, McGraw-Hill, New York, 1946.

21. Roper, F. G., Combust. Flame 29:219 (1977).

22. Spalding, D. B., Combustion and Mass Transfer, Pergamon, New York, 1979, p. 185.

23. Kuo, K. K., Principles of Combustion, John Wiley \& Sons, New York, 1986, p. 360.

24. Klajn, M., and Oppenheim, A. K., Nineteenth Symposium (Intemational) on Combustion, The Combustion Institute, Pittsburgh, 1982, p. 223.

25. Li, S. C., Gordon, A. S., and Williams, F. A., Combust. Sci. Tech. 104:75 (1995).

26. Ban, H., Venkatesh, S., and Saito, K., J. Heat Trans. 116:954 (1994).

27. Urban, D. L., Yuang, Z.-G., Sunderland, P. B., Linteris, G. T., Voss, J. E., Lin, K.-C., Dai, Z., Sun, K., and Faeth, G. M., ALAA J. 36:1346 (1998).

28. Braun, W. G., Danner, R. P., and Daubert, T. E., Technical Data Book-Petroleum Refining, 3rd ed., American Petroleum Institute, Washington, 1976, Chapters 11 and 13.

Received 6 May 1998; revised 22 June 1998; accepted 25 June 1998. 